\title{
Development of antibacterial and UV protective cotton fabrics using plant food waste and alien invasive plant extracts as reducing agents for the in-situ synthesis of silver nanoparticles
}

\author{
Nina Čuk $\cdot$ Martin Šala $\cdot$ Marija Gorjanc $\mathbb{D}$
}

Received: 28 September 2020/Accepted: 22 January 2021 / Published online: 11 February 2021

(C) The Author(s) 2021

\begin{abstract}
The development of cellulose-based textiles that are functionalised with silver nanoparticles (AgNP), synthesised according to a green approach, and offer protection against ultraviolet (UV) radiation and pathogenic bacteria is very important today. In the present work we demonstrate the environmentally friendly approach to obtain such textile material by AgNP synthesis directly (in-situ) on cotton fabrics, using water extracts of plant food waste (green tea leaves, avocado seed and pomegranate peel) and alien invasive plants (Japanese knotweed rhizome, goldenrod flowers and staghorn sumac fruit) as reducing agents. The extracts were analysed for their total content of phenols and flavonoids and their antioxidant activity. The synthesised AgNP on cotton were round, of different size and amount depending on the reducing agent used. The highest amount of AgNP was
\end{abstract}

found for samples where Japanese knotweed rhizome extract was used as reducing agent and the lowest where extracts of goldenrod flowers and green tea leaves were used. Regardless of the reducing agent used to form AgNP, all cotton samples showed excellent protection against $E$. coli and $S$. aureus bacteria and against UV radiation with UV protection factor values above 50. The best results for UV protection even after the twelve repetitive washing cycles were found for the sample functionalized with AgNP synthesised with an extract of the Japanese knotweed rhizome. Due to the presence of AgNP on cotton, the air permeability and thermal conductivity decreased. AgNP had no effect on the change in breaking strength or elongation of fabrics.

\footnotetext{
N. Čuk · M. Gorjanc ( $\bowtie)$

Faculty of Natural Sciences and Engineering, University of Ljubljana, Aškerčeva 12, 1000 Ljubljana, Slovenia e-mail: marija.gorjanc@ntf.uni-lj.si

M. Šala

National Institute of Chemistry, Hajdrihova 19, 1000 Ljubljana, Slovenia
} 


\section{Graphic abstract}

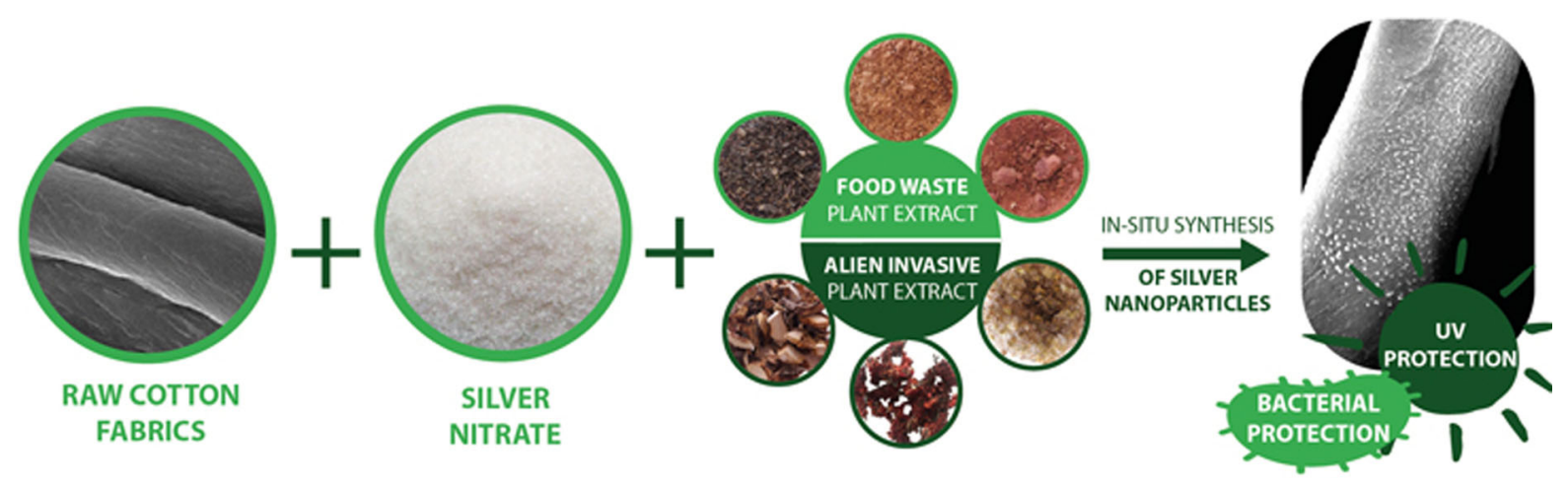

Keywords Cotton - Phytosynthesis - Silver nanoparticles - Invasive plant species · Food waste . UV protection - Antibacterial protection . Antioxidative properties $\cdot$ Mechanical properties

\section{Introduction}

Cotton is the most widely used natural cellulosic fibrous material for textile and apparel manufacturing, and its modification is driven by growing consumer demand for improved functions of conventional textile products (Tang et al. 2017). Cotton fibres are inherently nutritious and hydrophilic and therefore provide an excellent environment for the growth of bacteria and fungi (Ravindra et al. 2010), and they do not in themselves have an effective barrier to UV radiation, especially when undyed or dyed in light shades (Czajkowski and Paluszkiewicz 2008). Silver nanoparticles (AgNP) applied on cotton have been found to play an important role in developing protective properties against pathogenic bacteria (Bachir and Abouni 2015; Ibrahim et al. 2020; Khalil et al. 2014; Barani and Mahltig 2020) and UV radiation (Rao et al. 2019; Aladpoosh et al. 2014). The application of AgNP on cotton fabrics can be carried out in two-step or one-step processes. In a two-step process, AgNP is first synthesised and then applied on cotton fabric (exsitu) (Perera et al. 2013; Elshaarawy et al. 2019; Chattopadhyay and Patel 2009, Ravindra et al. 2010, El-Shishtawy et al. 2011; Onitsuka et al. 2019; Cheng et al. 2020; Jha and Prasad 2016), whereas in a onestep process the nanoparticles are formed directly (insitu) on the cotton fabric (Shadid-ul-Islam and Kumar
2020; Shahid-ul-Islam et al. 2019; Mamatha et al. 2020; Rao et al. 2019). The latter procedure is more appropriate from an energy, time and environmental perspective (Rehan et al. 2017). Chemical methods for the synthesis of AgNP typically use toxic chemicals and non-polar solvents during synthesis and generate hazardous by-products, and thus a high-yield, nontoxic, reliable, biocompatible, cost-effective and environmentally friendly methods have been identified (Min-Ho et al. 2017; Cinelli et al. 2015), such as biological methods using bacteria, plant extracts, fungi and algae (Husen and Siddiqi 2014; Mohammadinejad et al. 2016; Kausar et al. 2016; Dahoumane et al. 2017). The method in which plant extracts are used as reducing, capping and stabilising agents is called phytosynthesis. The exact mechanism of metal nanoparticle formation during phytosynthesis is not yet understood, but it is assumed that primary (sugars, peptides, amino acids, etc.) and secondary (flavonoids, terpenoids, alkaloids, polyphenols) metabolites of the biomass source act as reducing and stabilising agents and are responsible for the synthesis of metal NPs (Reddy et al. 2015). In many studied approaches to green in-situ AgNP phytosynthesis, the aggressive chemicals were used to prepare plant extracts, e.g. in methanol, ethanol and hexane as solvents, or in the presence of sodium hydroxide or acetic acid, and therefore cannot be considered as fully green synthesis processes (Rehan et al. 2020; Yu et al. 2020; Logeswari et al. 2015; Velmurugan et al. 2017; Tania et al. 2018). However, there are some studies in which only silver precursors and plant water extracts (i.e. aloe vera, red sanders powder and Keliab stones) were used to produce AgNP directly on cellulosic substrates (Zhou et al. 2017; Rao et al. 2019; Aladpoosh et al. 
2014). Although the researchers were successful forming AgNP on textiles and thus produce textiles with good protective properties, the preparation methods were energy and time consuming, such as the preparation of the textiles before synthesis, the longer extraction times of the plants and the treatment of the textiles in precursor or extract solutions at higher temperatures and/or over a longer period of time. In addition, only one plant material was investigated, using rather high concentrations of plant material, and no comparison was made with textiles functionalised with extracts only.

The plant materials considered as waste, i.e. plant material from inedible food processing by-products and invasive, non-native (alien) plant species (IAPS), whose introduction into our ecosystem causes economic or ecological damage, could be considered a more sustainable, cheaper and environmentally friendly source of phytoreducing agents, and this is a relatively new and unexplored area of nanoscience in textile technology. Synthesis of AgNP using IAPS has been previously reported with extracts of mimosa (Ganaie et al. 2015), Chinese yam (Maheswari 2012), Prosopis juliflora (Malini et al. 2020), coral vine (Ganaie et al. 2019) and Bauhinia variegata (Govindarajan et al. 2016), while only one report on the use of IAPS (sumac leaves) for in situ synthesis of AgNP on textiles was found, published by our group (Filipic et al. 2020). Food waste has also been used to produce AgNP, e.g. banana peel (Ibrahim 2015), eggplant calyx (Attia et al. 2020), pomegranate peel (Ahmad et al. 2012), pineapple peel (Das et al. 2019), onion peel (Yap et al. 2020), and papaya fruit (Jain et al. 2009), but only few reports have been published using plant food wastes (i.e., pomegranate peel, tamarind seed peel, red peanut hulls) for the in-situ synthesis of AgNP on cellulosic materials (Shahid-ul-Islam et al. 2019; Sheikh and Bramhecha 2019; Rehan et al. 2020). Various methods were applied, such as the immersion of cotton in $\mathrm{AgNO}_{3}$ solution and the subsequent dropwise addition of methanol/water (8:2) pomegranate peel extract (Shahid-ul-Islam et al. 2019), the pre-treatment of linen fabric with a chitosan-based formulation for the in-situ synthesis of AgNP using tamarind husk extract (Sheikh and Bramhecha 2019) and the microwave-assisted extraction of peanut hulls in water, ethanol and hexane for simultaneous dyeing and in-situ synthesis of AgNP (Rehan et al. 2020). All this research is interesting, innovative and delivers good results overall. However, from an environmental and health point of view, the use of volatile solvents should be completely avoided and more different waste plant materials should be studied.

The aim of our research was to develop a cotton fabric with multi-protective properties achieved by the environmentally friendly in-situ synthesis of silver nanoparticles. The goal was to investigate the potential of six plant materials that are now considered waste, i.e., plant material from food waste (e.g., green tea, avocado seed and pomegranate peel) and invasive plant material (e.g., Japanese knotweed rhizome, goldenrod flowers and staghorn sumac fruit) as reducing agents for the formation of silver nanoparticles directly on cotton fabrics, thus obtaining cellulosic textiles that provide excellent protection against UV radiation as well as against Escherichia coli and Staphylococcus aureus bacteria. In order to confirm the protective properties of the cotton fabrics due to the synthesized AgNP in-situ, the analysis of cotton fabrics treated only with water extracts was also performed. Furthermore, it is assumed that not all plant extracts have the same ability to form stable AgNP on cotton fabrics and it is also assumed that not all the analysed fabrics have excellent protective properties.

\section{Experimental}

\section{Material}

Plain weaved $100 \%$ raw cotton fabric was used for the research (warp 53 threads/cm, weft 29 threads $/ \mathrm{cm}$, $136.8 \mathrm{~g} / \mathrm{m}^{2}$ ). The fabric was supplied by Tekstina d.d., Slovenia.

Preparation of reducing agents (plant extracts)

The reducing agents for the in-situ synthesis of AgNP on cotton were prepared as water extracts from three vegetable food wastes, namely green tea leaves (Camellia sinensis), avocado seed (Persea americana) and pomegranate peel (Punica granatum) and from three invasive alien species, namely the Japanese knotweed rhizome (Fallopia japonica), the staghorn sumac fruit (Rhus typhina) and goldenrod flowers (Solidago canadensis). The dried plant materials were 
ground to a powder using a mixer and the extracts were prepared by immersing $20 \mathrm{~g} / \mathrm{l}$ powder of each plant in cold distilled water. The temperature of the solutions was raised to boiling point and kept at this temperature for $5 \mathrm{~min}$, after which all solutions were allowed to cool for two hours and then filtered.

In-situ synthesis of silver particles on cotton

The raw cotton fabrics were first immersed for $10 \mathrm{~min}$ in a precursor solution of $0.01 \mathrm{M}$ silver nitrate ( $\geq 99.8 \% \quad \mathrm{AgNO}_{3}$, Sigma-Aldrich, UK) at room temperature, wrung out on padder rollers (foulard) (Mathis, Switzerland) with a wet pick-up of $100 \%$ and then immersed for $60 \mathrm{~min}$ in the reducing agent bath (plant extract) at $60{ }^{\circ} \mathrm{C}$. The ratio between the mass of the reducing agent bath and the mass of fabric was 20:1. The functionalized samples were then rinsed in cold deionized water and air-dried at room temperature. The schematic representation of the process is shown in Fig. 1.

Functionalisation of cotton with reducing agent

To determine the influence of the reducing agent on the protective properties of cotton, cotton samples were also treated with reducing agents exclusively. The functionalisation was carried out in stainless steel flasks of the Gyrowash apparatus (James Heal, UK) at $60{ }^{\circ} \mathrm{C}$ for $60 \mathrm{~min}$. The liquor to goods ratio was 20:1. Afterwards the samples were rinsed in cold deionized water and air dried at room temperature.

Durability to washing

Cotton fabrics have been repeatedly washed in the laboratory device Gyrowash (James Heal, UK) according to the standard EN ISO 105-C06 standard, with $4 \mathrm{~g} / \mathrm{l} \mathrm{ECE}$ phosphate reference detergent B (SDC Enterprises Limited, UK). The washing was carried out at $40{ }^{\circ} \mathrm{C}$ for $30 \mathrm{~min}$. After washing, the samples were rinsed in distilled water and air dried at room temperature.

\section{Colour measurements}

The colour coordinates (CIE L*a*b) were determined on functionalised cotton fabrics with the Spectraflash reflectance spectrophotometer SF 600 PLUS-CT
(Datacolor, USA). The colour measurements were performed with a $9 \mathrm{~mm}$ aperture using four fabric layers. The specular component of the spectrophotometer was included and ten measurements were made on each sample under D65 illumination and $10^{\circ}$ standard observer.

\section{Measurements of the UV protection factor}

The transmittance of cotton fabrics for UV radiation (UVA and UVB) was measured with a Varian Cary UV/VIS spectrometer (Agilent, USA) equipped with the integrating sphere DRACA301 and operated with the software Solarscreen. The UV protection factor (UPF) of the measured samples was calculated according to the AATCC TM 183 standard.

Antibacterial analysis

Cotton samples were tested for their antibacterial properties against Staphylococcus aureus (S. aureus) and Escherichia coli (E. coli) according to the standard test method ASTM E2149-13 under dynamic contact conditions. The analysis was performed by a certified laboratory according to the protocol (National Laboratory of Health, Environment and Food, Maribor, Slovenia).

\section{Antioxidant activity (DPPH assay)}

The antioxidant activity of cotton samples was analysed using the 1,1-diphenyl-2-picrylhyrazyl (DPPH) method for scavenging free radicals (Singh and Sheikh 2020; Jadav and Ninge 2017; Türkoğlu et al. 2017). Cotton samples were allowed to react for $30 \mathrm{~min}$ with $0.1 \mathrm{mM}$ ethanolic solution of DPPH at $37{ }^{\circ} \mathrm{C}$ in the dark under shaking conditions. The absorbance of reaction solutions at $517 \mathrm{~nm}$ was measured with the UV/VIS spectrometer Varian Cary. The antioxidant activity was calculated according to the following equation:

Antioxidant activity $(\%)=[(\mathrm{Ac}-\mathrm{As}) / \mathrm{Ac}] \times 100$

where Ac is absorbance of blank DPPH solution and As is absorbance of DPPH solution in the contact with functionalised cotton fabric (Singh and Sheikh 2020). 

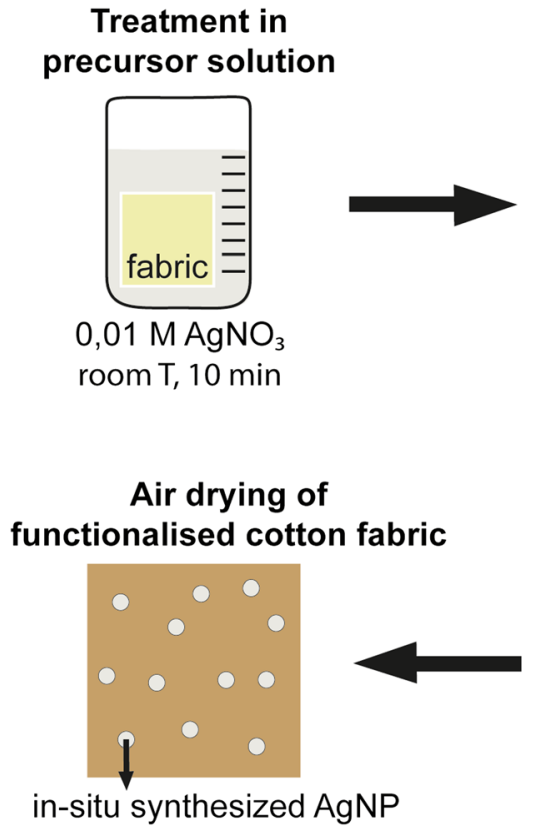
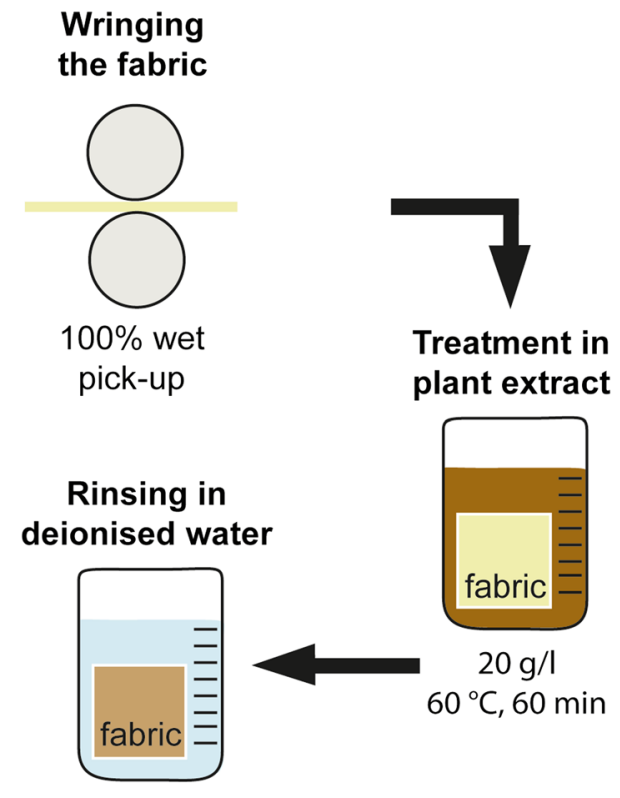

Fig. 1 Schematic presentation of in-situ synthesis of silver nanoparticles on cotton fabric

HPLC-MS analysis

HPLC-MS measurements were performed on an UltiMate 3000 UHPLC system (Thermo Scientific, U.S.A.) coupled with a triple quadrupole/linear ion trap mass spectrometer (4000 QTRAP LC-MS/MS System; Applied Biosystems/MDS Sciex, Ontario, Canada). The analysis was performed in positive MRM. Methanol (Chromasolv LC-MS grade, Fluka, Switzerland) and water purified on a Milli-Q system from Millipore (Bedford, MA, USA) were used to prepare mobile phases, and formic acid from Fluka was used as modifier. An analytical HPLC column Hypersil GOLD Aq, $(3 \mathrm{~mm} \times 150 \mathrm{~mm}, 3 \mu \mathrm{m}$ particle size, Thermo) with the flow rate of $0.3 \mathrm{ml} / \mathrm{min}$ was used. A mobile phase consisting methanol and water, both modified with $0.1 \%$ formic acid, was used throughout the work. Injection volume and column temperature were $10 \mu \mathrm{l}$ and $30{ }^{\circ} \mathrm{C}$, respectively.

The total phenolic content (TPC) and total flavonoid content (TFC) of extracts

The TPC and TFC of plant extracts was determined according to the methods described by Katırc1 et.al (2020). Folin-Ciocalteu method was used to determine the TPC of plant extracts. Clear supernatants
$(0.5 \mathrm{ml})$ were transferred into test tubes and FolinCiocalteu agent $(2.5 \mathrm{ml})$ was added to each tube. After $3 \mathrm{~min}, 2 \mathrm{ml}$ of $\mathrm{Na}_{2} \mathrm{CO}_{3}(20 \%)$ solution was added and the mixture was kept in dark for $2 \mathrm{~h}$. Finally, the absorbances were determined at a wavelength of $760 \mathrm{~nm}$ using a UV-Vis spectrophotometer (Perkin Elmer, Lambda 25). A linear calibration curve was obtained with gallic acid, and the results were expressed as $\mathrm{mg}$ gallic acid equivalents (GAE) per $100 \mathrm{~g}$ of plant extract samples. If necessary, the extracts were diluted in 5 to 10 -fold ratio. To determine the TFC contents of plant extracts the catechin solution was used as the standard in the calibration curve. A sample of $1 \mathrm{ml}$ of the prepared extract or standard was mixed with $4 \mathrm{ml}$ of distilled water and $0.3 \mathrm{ml}$ of $5 \% \mathrm{NaNO}_{2}$. After 5 and $1 \mathrm{~min}$, $0.3 \mathrm{ml}$ of $10 \% \mathrm{AlCl}_{3}$ and $2 \mathrm{ml}$ of $1 \mathrm{M} \mathrm{NaOH}$ were added, respectively. Then, $2.4 \mathrm{ml}$ of distilled water was added, and the mixture was shaken. The pink colour formed was read at a wavelength of $510 \mathrm{~nm}$ using a spectrophotometer and the results were expressed as mg catechin equivalent (CE) per $100 \mathrm{~g}$ sample. 
Inductively coupled plasma mass spectrometry (ICP-MS)

All reagents used were of analytical grade or better. Ultrapure water (MilliQ, Millipore, Germany) and ultrapure acids (HNO3, Merck-Suprapure, Germany) were used for sample dilution and preparation of standards. Standards were prepared in-house by dilution of certified, traceable, inductively coupled plasma (ICP)-grade single-element standards (Merck CertiPUR). An Agilent Technologies 7500ce ICP-mass spectrometry (MS) instrument, equipped with a MicroMist glass concentric nebuliser and Peltiercooled, Scott type spray chamber was used. Prior to ICP-MS analysis, each sample was weighted (approximately $100 \mathrm{mg}$ ) and digested using a microwaveassisted digestion system (CEM MDS-2000, USA) and a solution of $7 \mathrm{ml}$ nitric acid and $1 \mathrm{ml}$ hydrogen peroxide. The digested samples were cooled to room temperature and then diluted with $2 \% \mathrm{v} / \mathrm{v}$ nitric acid until their concentration was within the desired concentration range. The digestion procedure yielded clear solutions that were used in subsequent analyses.

\section{Scanning electron microscopy (SEM)}

The surface of the cotton fibres was imaged using a scanning electron microscope JEOL JSM 6060 LV SEM (Japan) in low vacuum mode. The samples were coated with a $10 \mathrm{~nm}$ thick layer of $\mathrm{Au} / \mathrm{Pd}$ alloy (90\%/ $10 \%$ ) before observations. The size of the formed nanoparticles was analysed using Image J programme.

Physical, thermal and mechanical analysis

The air permeability ( $1 / \mathrm{min})$ of the fabrics was measured using an air permeability tester Mesdan AIR TRONIC Code 3240B according to the standard procedure ISO 9273 (Stankovic et al. 2019). Thermal properties in the form of thermal conductivity (W/mK) of cotton fabrics was carried out using Lee's disc method, where the heat is transferred across the thickness of the sample between two blocks of different temperatures controlled by thermostats. The apparatus is described in detail in (Karkri et al. 2015). The temperature of upper block was $20{ }^{\circ} \mathrm{C}$ and that of the lower block was $60{ }^{\circ} \mathrm{C}$. The mechanical properties of the fabrics were analysed in terms of breaking strength $(\mathrm{N})$ and breaking elongation (\%) according to the standard ISO 13934-1:1999, on Instron 6022 instrument (Gorjanc et al. 2014).

\section{Results and discussion}

In-situ phytosythesis of AgNP on cotton fabric was performed using extracts of plant materials from food waste and invasive alien species. The photographs of untreated and differently functionalised samples are shown in Fig. 2. In the case where in-situ synthesis of AgNP on cotton fabric was performed, the colour change is obvious.

Figure 3 shows the measured colour values CIE $\mathrm{L}^{*} \mathrm{a} \mathrm{b}^{*}$ of differently functionalised cotton samples before and after repetitive washing. The samples functionalised with extracts from food waste (except avocado seed) are darker than those functionalised with extracts from invasive plant species. The colour of the samples functionalised only with plant extracts (reducing agents) depends on their dyeing capability, while the colour of the samples where in-situ synthesis was performed also depends on the presence of AgNP. When in-situ synthesis is performed, all samples become darker and redder. The differences between the samples are in the yellow-blue axis, i.e., the samples where green tea, staghorn sumac and goldenrod extracts were used as reducing agents become less yellow (the hue moves towards the blue axis), and when avocado, pomegranate and Japanese knotweed extracts were used as reducing agents, the samples become more yellow. Gonzalez et al. (2014) found that the optical properties of colloidal AgNP change with the shape and size of the nanoparticles, resulting in a range of colloidal samples from light yellow to dark red in colour. Therefore, the presence of AgNP in the water medium is observed as a change in colour of the medium. An indication of the presence of silver nanoparticles on the top layer of textiles is the appearance of a silver surface plasmon band with blue or red shifts as the particle size decreases or increases, respectively (Gorjanc et al. 2012). Loading of textiles with silver from colloidal solution causes yellowing of textiles (Yuranova et al. 2003; Gorenšek et al. 2010). After washing, the samples become lighter in colour, with the exception of the samples loaded with AgNP where pomegranate peel, Japanese knotweed rhizome and staghorn sumac fruit were used as reducing agents, they become darker. The reason 


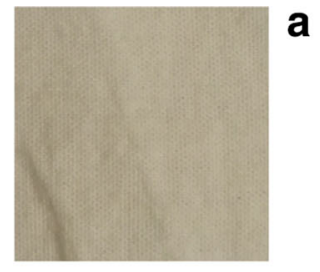

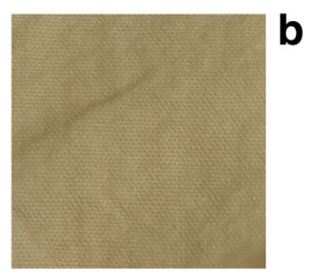
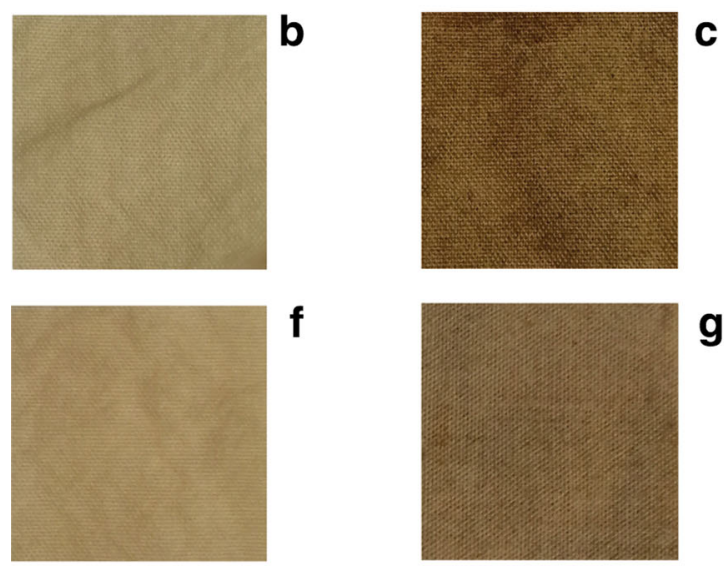

g

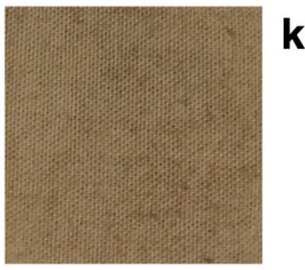

Fig. 2 The photographs of untreated and functionalised cotton fabrics: a untreated, b green tea extract, c $\mathrm{Ag}+$ green tea extract, $\mathbf{d}$ avocado seed extract, $\mathbf{e} \mathrm{Ag}+$ avocado seed extract, f pomegranate peel extract, $\mathbf{g ~ A g}+$ pomegranate peel extract,

for the darker coloration after washing is probably because the silver nanoparticles were exposed from bulk to the surface of the fabric during washing (Liu et al. 2014). These samples are also redder and yellower after washing.

The formation of nanoparticles on the surface of cotton fibres was also analysed by SEM. The samples functionalised only by the reducing agent (plant extracts) show no specific changes in the morphology of the fibres (Fig. 4a, c, e, g, i). However, the samples where the in-situ synthesis of AgNP on cotton was performed have visible round shaped nanoparticles deposited on the surface of the fibres (Fig. 4b, d, f, h). The formed nanoparticles are more or less homogeneously deposited on the fibres, and as can be seen from the SEM images, the quantity and size of the nanoparticles differ depending on the used green
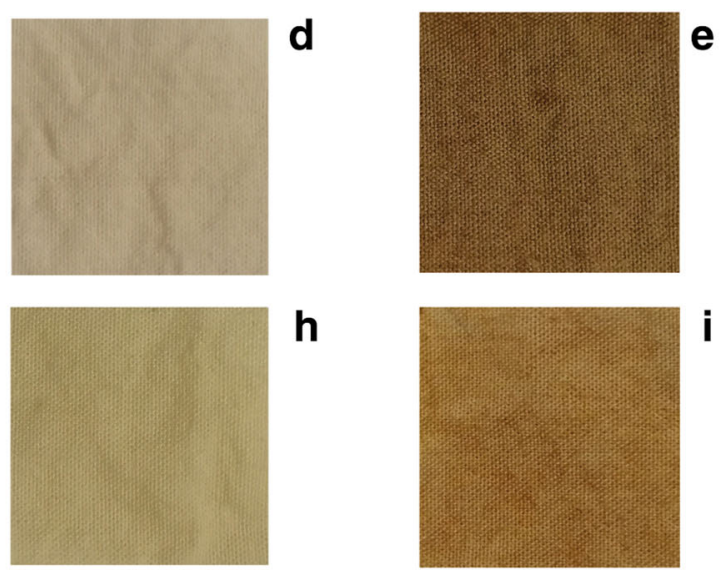

h
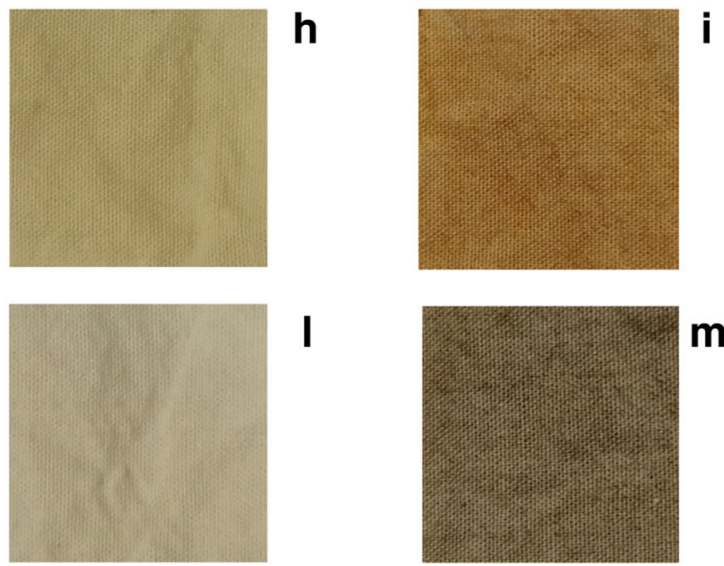

h Japanese knotweed rhizome extract, i Ag + Japanese knotweed rhizome extract, j staghorn sumac fruit extract, $\mathbf{k} \mathrm{Ag}+$ staghorn sumac fruit extract, $\mathbf{l}$ goldenrod flowers extract, $\mathbf{m ~ A g}+$ goldenrod flowers extract

reducing agent for an in-situ phytosynthesis. The proposed mechanism of AgNP formation on cotton is illustrated in Fig. 5. The mechanism is adapted from published research on ex-situ and in-situ green synthesis of AgNP (Annavaram et al. 2015; Yazdanshenas and Shateri-Khalilabad 2012; Dash et al. 2020; Sivaranjana et al. 2019). Regardless of the process used for the green synthesis of AgNP, their formation and stabilisation are determined by the biomolecules present in the extract, such as polyphenols and flavonoids. In the first step, when the cotton is immersed in the precursor solution, the hydroxyl groups $(-\mathrm{OH})$ of cellulose in the cotton react with $\mathrm{Ag}^{+}$ ions of $\mathrm{AgNO}_{3}$ to form nucleation sites for the nanoparticles. If the reduction process of $\mathrm{Ag}^{+}$is not continued, the nanoparticles will not form even if the fabric remains in the $\mathrm{AgNO}_{3}$ solution for a few days 

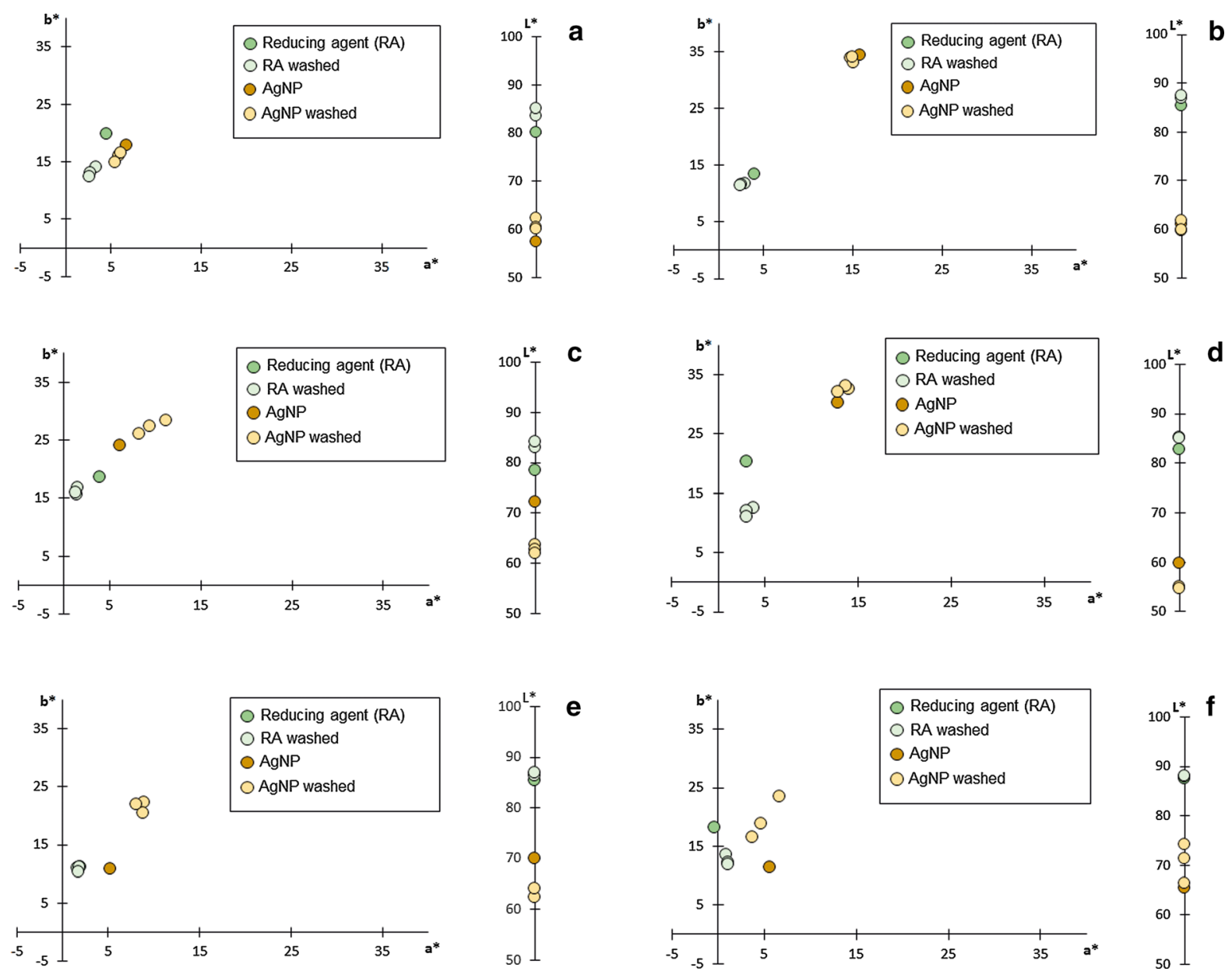

Fig. 3 CIE L*a*b* colour values of cotton fabrics functionalised with a green tea extract and $\mathrm{Ag}+$ green tea extract, b avocado seed extract and $\mathrm{Ag}+$ avocado seed extract, c pomegranate peel extract and $\mathrm{Ag}+$ pomegranate peel extract,

(Yazdanshenas and Shateri-Khalilabad 2012). Introduction of additional $-\mathrm{OH}$ and $-\mathrm{COOH}$ groups from biomolecules of plant extracts promotes the synthesis of nanoparticles (Annavaram et al. 2015; Sivaranjana et al. 2019), and after rinsing with water, the reaction impurities are removed from the surface.

The quantity of silver and the size of nanoparticles on the cotton samples were analysed by ICP-MS and SEM, and the images were processed by ImageJ programme. The results are presented in Table 1. The plant extract used as reducing agent affects the size and mean particle size of the synthesised AgNP. The highest quantity of silver was detected for the sample where in-situ phytosynthesis was performed by using

Japanese knotweed rhizome extract $(2.4 \mathrm{mg} / \mathrm{g})$, and the mean size of nanoparticles was one of the highest (109 to $176 \mathrm{~nm}$ ). Larger nanoparticles were found on the sample where in-situ synthesis was performed using pomegranate peel extract as reducing agent (from 124 to $154 \mathrm{~nm}$ ), but the quantity of silver was lower $(0.8 \mathrm{mg} / \mathrm{g})$. A similar quantity of silver was found on the other two samples where phytosynthesis was performed by using food waste extracts as reducing agents $(0.8 \mathrm{mg} / \mathrm{g}$ for green tea leaves and $1.0 \mathrm{mg} / \mathrm{g}$ for avocado seed). Here, the smallest nanoparticles were formed with an average particle size of 84-103 nm. In-situ synthesis using extracts of staghorn sumac fruit and goldenrod flowers as 
Fig. 4 SEM images of fibres of cotton fabrics functionalised with a green tea extract, $\mathbf{b} \mathrm{Ag}+$ green tea extract, $\mathbf{c}$ avocado seed extract, d Ag + avocado seed extract, e pomegranate peel extract,

f $\mathrm{Ag}+$ pomegranate peel extract, $\mathbf{g}$ Japanese knotweed rhizome extract, h Ag + Japanese knotweed rhizome extract, i staghorn sumac fruit extract,

j Ag + staghorn sumac fruit extract, $\mathbf{k}$ goldenrod flowers extract, $\mathbf{l ~ A g ~ + ~ g o l d e n r o d ~}$ flowers extract
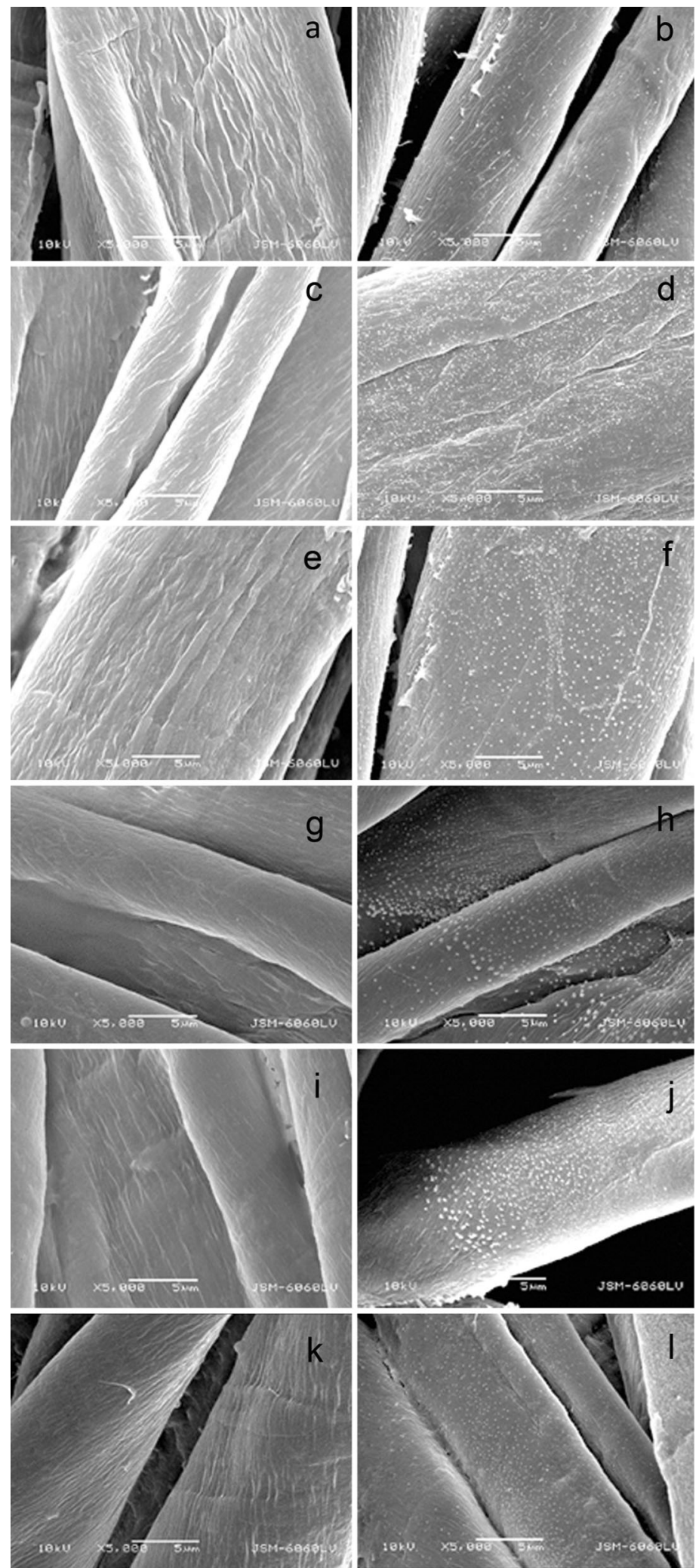
Table 1 Content of silver $(\mathrm{Ag})$ on cotton fabrics $(\mathrm{mg} /$ g) and mean minimum and maximum Ag particle size (nm)

${ }^{\mathrm{a}}$ Value under the limit of detection

\begin{tabular}{llll}
\hline Sample & $\mathrm{Ag}(\mathrm{mg} / \mathrm{g})$ & \multicolumn{2}{l}{ Mean particle size $(\mathrm{nm})$} \\
\cline { 3 - 4 } & & Minimum & Maximum \\
\hline Untreated & $-{ }^{\mathrm{a}}$ & - & - \\
$\mathrm{Ag}+$ green tea & 0.8 & 84 & 103 \\
$\mathrm{Ag}+$ avocado seed & 1.0 & 89 & 102 \\
$\mathrm{Ag}+$ pomegranate peel & 0.8 & 124 & 154 \\
$\mathrm{Ag}+$ Japanese knotweed rhizome & 2.4 & 109 & 176 \\
$\mathrm{Ag}+$ staghorn sumac fruit & 1.4 & 112 & 218 \\
$\mathrm{Ag}+$ goldenrod flowers & 1.5 & 90 & 113 \\
\hline
\end{tabular}

reducing agents gives similar results in the amount of $\mathrm{Ag}$ on the samples (1.4 and $1.5 \mathrm{mg} / \mathrm{g}$, respectively), but the size of the nanoparticles differs significantly. The size of the nanoparticles formed using staghorn sumac fruit extract as reducing agent ranges from 112 to $218 \mathrm{~nm}$, while the mean size of the nanoparticles using goldenrod flowers extract as reducing agent ranges from 90 to $113 \mathrm{~nm}$.

According to Huang et al. (2007) the concentration of active compounds in the plant extract affects the formation of $\mathrm{AgNP}$, the time required for the formation of nanocrystals, their final concentration, size, shape, and their tendency to aggregate. Table 2 shows the results of the HPLC-MS analysis of the plant water extracts. For the HPLC-MS analysis, the most abundant and frequently found metabolites in the literature, which have been used in similar studies, were selected for analysis. The identification of these biomolecules indicates their successful isolation in water media, implying that the compounds are polar in nature. The concentrations of biomolecules in the extracts varied depending on the plant species. Additionally, some extracts contain some biomolecules that others do not, i.e., resveratrol, which was found only in the Japanese knotweed rhizome extract, or vitexin, found only in green tea leaves extract. However, we believe that the HPLC-MS method is not suitable to be applied here, because over hundreds of biomolecules are present in the extracts and occur as a combination of different types of bioactive compounds, their separation still remains as big challenge for the process of identification and characterization of all of them (Boligon and Athayde 2014) and in the end, the total phenols and flavonoids promote the formation of nanoparticles (Huang et al. 2007). For this reason, the total phenolic content (TPC) and total flavonoid content (TFC) of the plant extracts were studied, and the results are presented in Table 3.

The highest concentration of phenolic compounds in plant extracts was found for pomegranate peel extract (1635.1 mg GAE/100 g) and the lowest for goldenrod flowers extract (179.5 mg GAE/100 g), while the highest concentration of flavonoids was found for avocado seed extract (400.6 mg CE/100 g) and the lowest for staghorn sumac fruit (110.6 mg CE/ $100 \mathrm{~g}$ ). The ratio between TPC and TFC among plant extracts is also different, i.e. avocado seed and goldenrod flowers extracts have higher concentrations of TFC than TPC, while other plant extracts have higher concentrations of TPC than TFC. The results of ICP-MS (the quantity of Ag on cotton) and results of TPC, TFC do not agree, i.e., the extracts with the highest TPC content (green tea leaves and pomegranate peel) have the lowest content of Ag. Therefore, it is not possible to predict from HPLC-MS, TPC and TFC which plant extract is more suitable to promote AgNP formulation on cotton fabric. In this study, AgNPs were synthesised directly on cotton by immersing the fabric in the $\mathrm{AgNO}_{3}$ solution, wringing it out, and then immersing it in a plant extract bath. In the first phase, the $\mathrm{Ag}^{+}$ions from the precursor bath were adsorbed onto the hydroxyl groups $(-\mathrm{OH})$ of cellulose. But not all-OH sites were occupied by $\mathrm{Ag}^{+}$, some were later occupied with biomolecules from the extract, as it is also evident from the CIE L*a*b* results (Fig. 3). The biomolecules of the plant extracts are consumed in two reactions, one is nanoparticle formation, and the other is adsorption on cellulose. Moreover, not all the nucleation sites for AgNP formation were changed into nanoparticles, many 


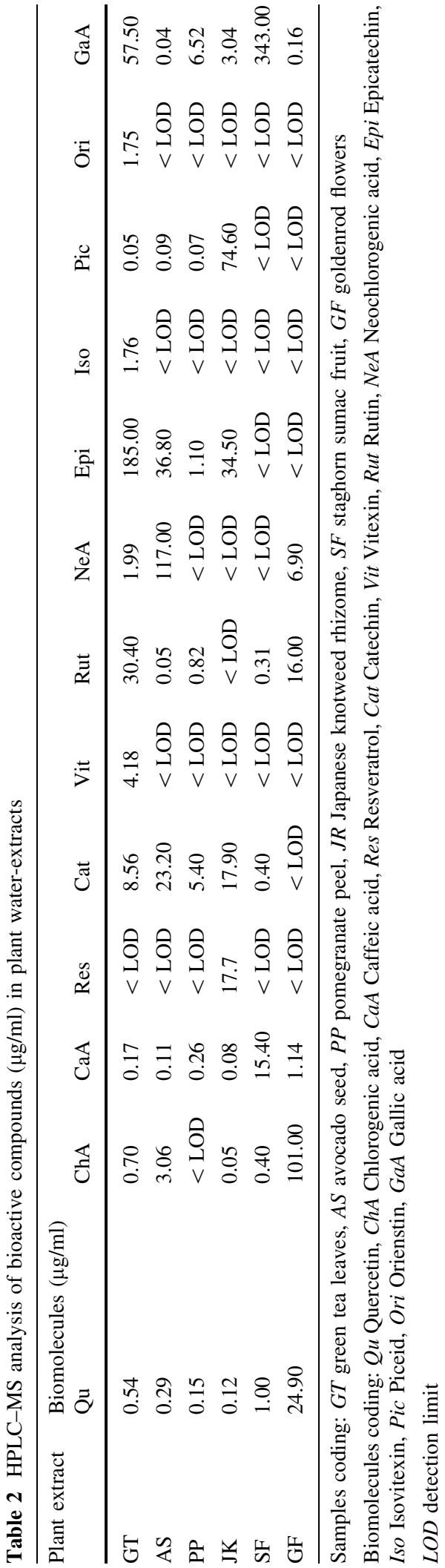

Table 3 The total phenolic content (TPC) and total flavonoid content (TFC) of the extracts

\begin{tabular}{lcl}
\hline Plant extract & TPC $(\mathrm{mg}$ GAE/ & $\begin{array}{l}\text { TFC }(\mathrm{mg} \mathrm{CE} / \\
100 \mathrm{~g})\end{array}$ \\
\hline Green tea leaves & 747.3 & 312.4 \\
Avocado seed & 292.3 & 400.6 \\
Pomegranate peel & 1635.1 & 356.5 \\
Japanese knotweed & 224.7 & 224.1 \\
$\quad$ rhizome & & \\
Staghorn sumac fruit & 526.1 & 110.6 \\
Goldenrod flowers & 179.5 & 210.0 \\
\hline
\end{tabular}

remained as complexes between biomolecule and silver. The phytosynthesis of AgNP is determined not only by the concentration of biomolecules but also by the reaction rate depending on the plant extract used. Akbal et al. (2016) investigated the reaction rate for the formation of AgNP in solution using different plant extracts. They found that the nucleation and growth processes of $\mathrm{AgNP}$ in the mixture of $\mathrm{AgNO}_{3}$ solution and the plant leaf extracts were time-dependent processes. While some plant extracts complete the formation of $\mathrm{AgNP}$ in $30 \mathrm{~min}$, some require more than $120 \mathrm{~min}$ for this process. To confirm this, we performed the analysis of antioxidant activity of functionalised textiles. The reduced concentration of active biomolecules either in the extract or on functionalised textile (i.e. due to consumption for AgNP formation), decreases the antioxidant activity (Firoozi et al. 2016). The antioxidant activity of functionalised cotton fabrics with in-situ synthesised AgNP was evaluated by $\mathrm{DPPH}^{*}$ assay, which is a widely used method to evaluate the ability of antioxidants to scavenge free radicals, known to be an important factor in biological damage caused by oxidative stress (Sahgal et al. 2009). This method gives information about the antioxidant ability of the tested compounds as the DPPH radical reacts with the hydrogen donor species such as phenols and flavonoids present in the extract (Grace-Lynn et al. 2012; Huang et al. 2005; Parthasarathy et al. 2009). The antioxidant activity of various plant extracts is high (Fig. 6). The antioxidant properties of AgNP-functionalised cotton fabrics decrease, which is attributed to decreased concentration of free plant biomolecules on the surface of textile due to their adsorption onto 
Fabric

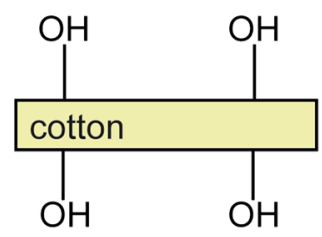

Formed AgNP on fabric
Nucleation of AgNP

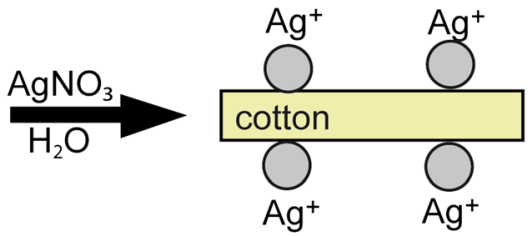

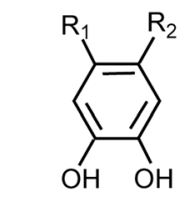

Plant extract

AgNP formation
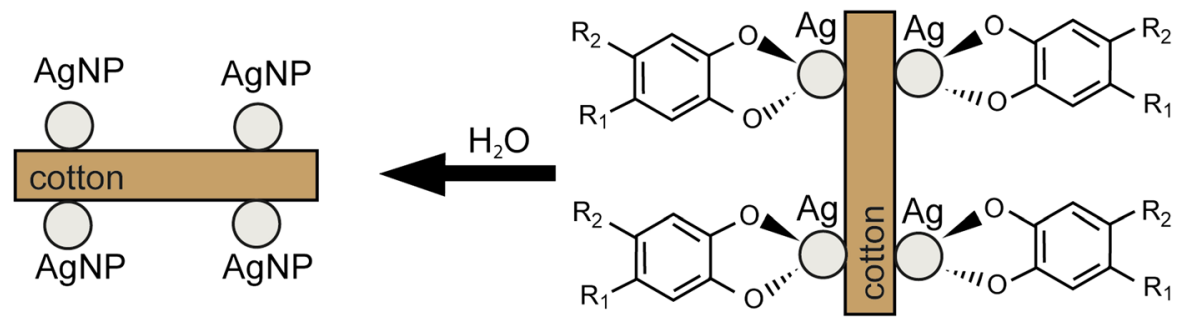

Fig. 5 Schematic representation of the AgNP formation on the surface of cotton fabrics by plant extract

Fig. 6 Antioxidant activity of plant extracts and cotton fabric with in-situ synthesized AgNP (GT green tea leaves, $A S$ avocado seed, $P P$ pomegranate peel, $J R$ Japanese knotweed rhizome, $S F$ staghorn sumac fruit, $G F$ goldenrod flowers)

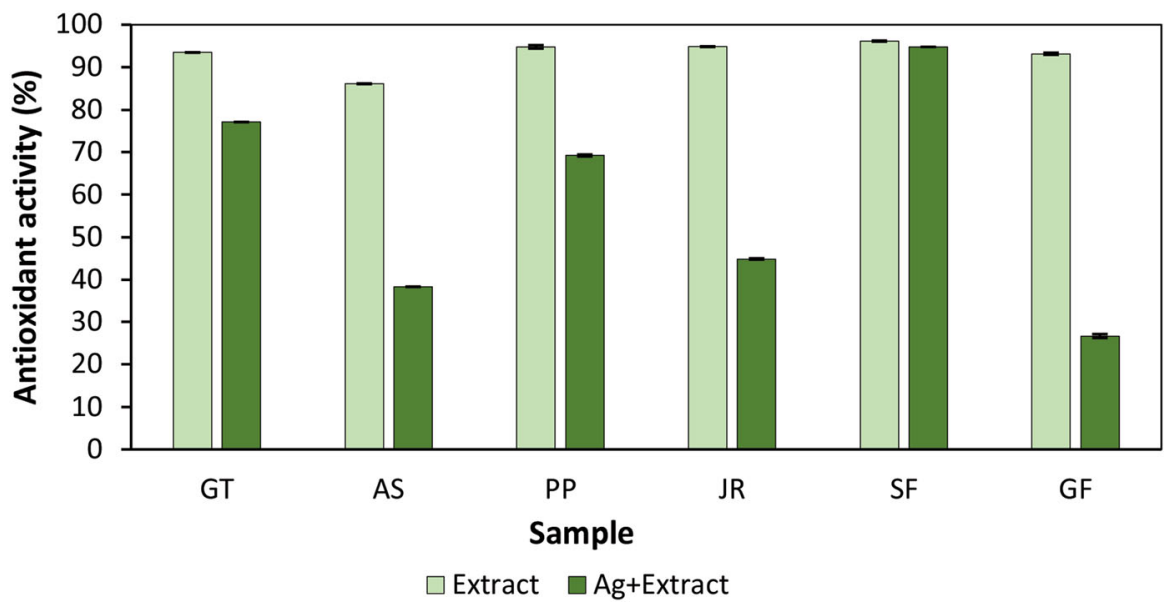

cotton and AgNP formation. This was also confirmed by results on the green synthesis of AgNP in solutions, where the antioxidant activity of extracts and $\mathrm{Ag} /$ extract was analysed (He et al. 2017; Kashkouli et al. 2018; Firoozi et al. 2016). Moreover, TPC and TFC were found to be lower in the case of $\mathrm{Ag} /$ extract suspensions than extracts alone (Firoozi et al. 2016).

The size and quantity of nanoparticles affect the functional properties of fabrics (Kert et al. 2014). In our case, the antibacterial properties of silver functionalised cotton fabrics against Gram-positive and
Gram-negative bacteria (Table 4) are all excellent, regardless of the quantity or size of AgNP. Silver nanoparticles have high activity against a wide range of microbes and parasites, and they act as a silver ion reservoir that continuously releases a high enough dose of silver antibacterial species into their environment to maintain activity for an extended period of time (Le Ouay and Stellacci 2015). The increased multidrug resistance of microorganisms and the fact that silver nanoparticles hold great promise in addressing this challenge (Tang and Zheng 2018), 
Table 4 Antibacterial properties of cotton samples, expressed as bacterial reduction (\%), content of silver (Ag) on samples (mg/kg) and mean minimum and maximum $\mathrm{Ag}$ particle size $(\mathrm{nm})$

\begin{tabular}{llc}
\hline Sample & Bacterial reduction $(\%)$ & E. coli \\
\cline { 2 - 3 } & S. aureus & $-^{\mathrm{a}}$ \\
\hline Untreated & $-^{\mathrm{a}}$ & 99 \\
$\mathrm{Ag}+$ green tea leaves & 97 & 100 \\
$\mathrm{Ag}+$ avocado seed & 100 & 100 \\
$\mathrm{Ag}+$ POMEGRANATE peel & 100 & 100 \\
$\mathrm{Ag}+$ Japanese knotweed rhizome & 98 & 100 \\
$\mathrm{Ag}+$ staghorn sumac fruit & 99 & 100 \\
$\mathrm{Ag}+$ goldenrod flowers & 100 & \\
\hline
\end{tabular}

${ }^{\mathrm{a}}$ No bacterial reduction

AgNP functionalised textiles can prevent various infections due to their antimicrobial properties (Bachir and Abouni 2015).

Figure 7 shows the UPF results before and after repetitive washing of samples functionalised by only reducing agent and samples where in-situ phytosynthesis was performed. In general, the cotton fabrics functionalised with in-situ synthesized AgNP show better UV protection properties than the samples treated with only reducing agent, and the overall rating is excellent (UPF > 50). The reason for the high UPF values of the samples treated with only reducing agent is due to the organic compounds of the natural extracts which act as UV absorbers (Sayed et al. 2015). The highest UPF value was obtained for the sample where in-situ synthesis of AgNP was carried out with pomegranate peel extract $(\mathrm{UPF}=292.96)$ and remained very high $(\mathrm{UPF}=157.81)$ even after twelve repetitive domestic washings. The UPF value of the sample functionalised by only pomegranate peel extract had also very high UPF initially (UPF = 259.77), but decreased rapidly with washing, and was only 28.34 after the twelfth wash. The in-situ synthesis of AgNP on cotton has the most striking change in UPF value when Japanese knotweed extract was used as a reducing agent. The UPF value of the sample functionalised with only extract was 27.50 and increased to a value of 164.43 when AgNP in-situ synthesis was performed. After the first wash, the UPF value of the latter sample decreases to a value of 99.66 and remains unchanged (UPF $=99.74)$ after the twelfth wash. All the samples, except the sample functionalised with only pomegranate peel extract, show overall excellent wash fastness properties as shown in Fig. 7. The best wash fastness properties were found for the samples where avocado seed extract was used as a reducing agent for the formation of AgNP directly on cotton. The UPF value decreased only slightly, from 92.95 to 85.12 .

Untreated and functionalised cotton fabrics were tested for their air permeability, thermal conductivity, and mechanical properties. The results of air permeability analysis are shown in Fig. 8. Air permeability decreases for all samples where in-situ synthesis of $\mathrm{AgNP}$ on cotton was performed, which is due to the presence of nanoparticles on and in the fibres. The same was found by others (Ali et al. 2018; Shaid et al. 2014; Noman et al. 2020; Ugur et al. 2010; Jiang et al. 2015). Although the air permeability is reduced for the samples with in-situ formed AgNP, the values are not much lower compared to the untreated sample, implying that the functionalised cotton fabrics still provide good comfort to the potential user. On the other hand, the thermal conductivity (Fig. 9) is greatly reduced for cotton fabrics where in-situ AgNP synthesis was performed, while there is no obvious difference between the samples treated with only plant extracts. Textiles with lower thermal conductivity have higher heat/thermal insulation properties that help the human body to reduce heat, and the incorporation of conductive nanomaterials into or onto textiles in an effective approach for producing thermal management materials without increasing the thickness of clothing or wearing more layers of clothing that, on the other hand, cause discomfort to the user (Liu et al. 2018; Wang et al. 2019; Park 2020).

The results of mechanical properties such as breaking strength and elongation of cotton fabrics 

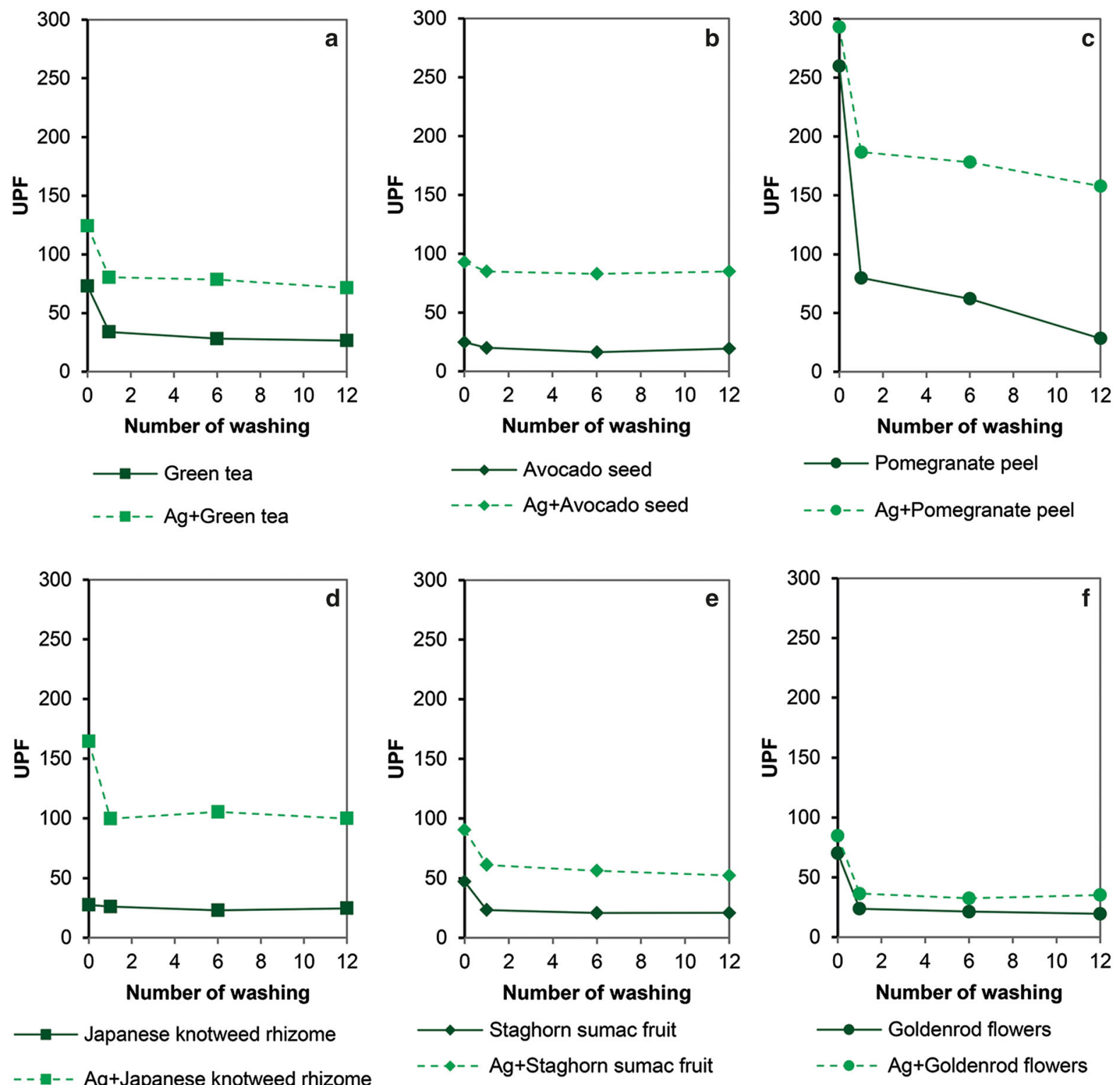

- - - - - Ag+Japanese knotweed rhizome

knotweed rhizome extract and $\mathrm{Ag}+$ Japanese knotweed rhizome extract, e staghorn sumac fruit extract and $\mathrm{Ag}+$ staghorn sumac fruit extract, $\mathbf{f}$ goldenrod flowers extract and $\mathrm{Ag}+$ goldenrod flowers extract extract and $\mathrm{Ag}+$ avocado seed extract, $\mathbf{c}$ pomegranate peel extract and $\mathrm{Ag}+$ pomegranate peel extract, d Japanese

are shown in Fig. 10. The results show that the change in mechanical properties is more related to the plant extract used than to the in-situ synthesis and formation of AgNP on the cotton itself. Regardless of the extract used, the breaking elongation increases for all the samples, which means that the functionalised cotton fabrics are slightly more stretchable than the untreated ones. The values of breaking strength vary depending on the plant extract used. The samples functionalised with green tea leaf extract and goldenrod flowers (samples GT, Ag + GT, GF and Ag + GF, Fig. 10) have very similar values of breaking strength as untreated sample (considering the standard deviation). The breaking strength increases for the samples 


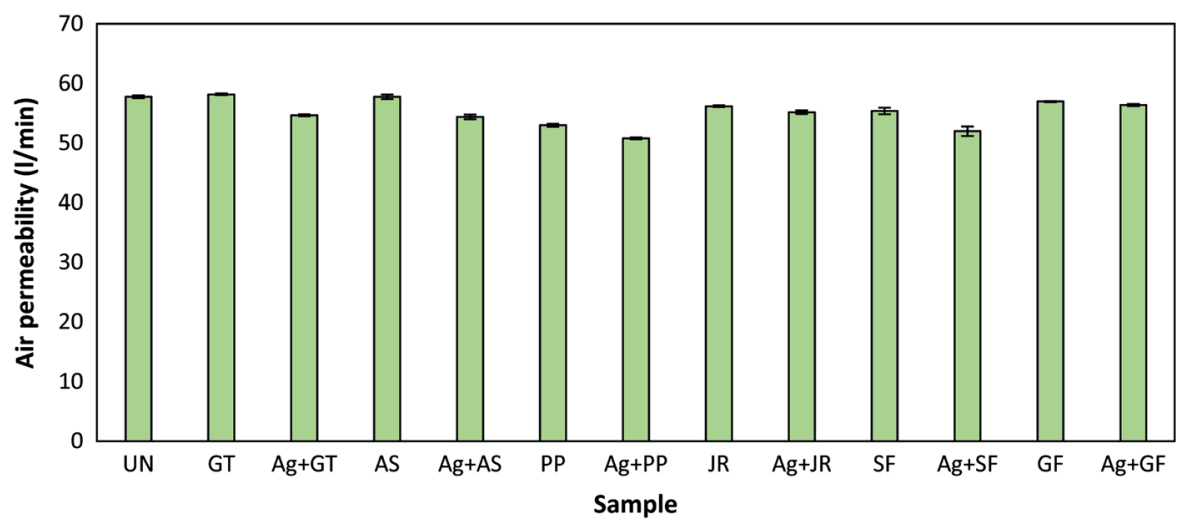

Fig. 8 Air permeability (1/min) of untreated and functionalised cotton fabrics: $U N$ untreated, $G T$ green tea extract, $A g+G T$ $\mathrm{Ag}+$ green tea extract, $A S$ avocado seed extract, $A g+A S$ $\mathrm{Ag}+$ avocado seed extract, $P P$ pomegranate peel extract, $A g+P P \quad \mathrm{Ag}+$ pomegranate peel extract, $J R$ Japanese knotweed rhizome extract, $A g+J P A g+$ Japanese knotweed rhizome extract, $S F$ staghorn sumac fruit extract, $A g+S F$ $\mathrm{Ag}+$ staghorn sumac fruit extract, $G F$ goldenrod flowers extract, $A g+G F \mathrm{Ag}+$ goldenrod flowers extract

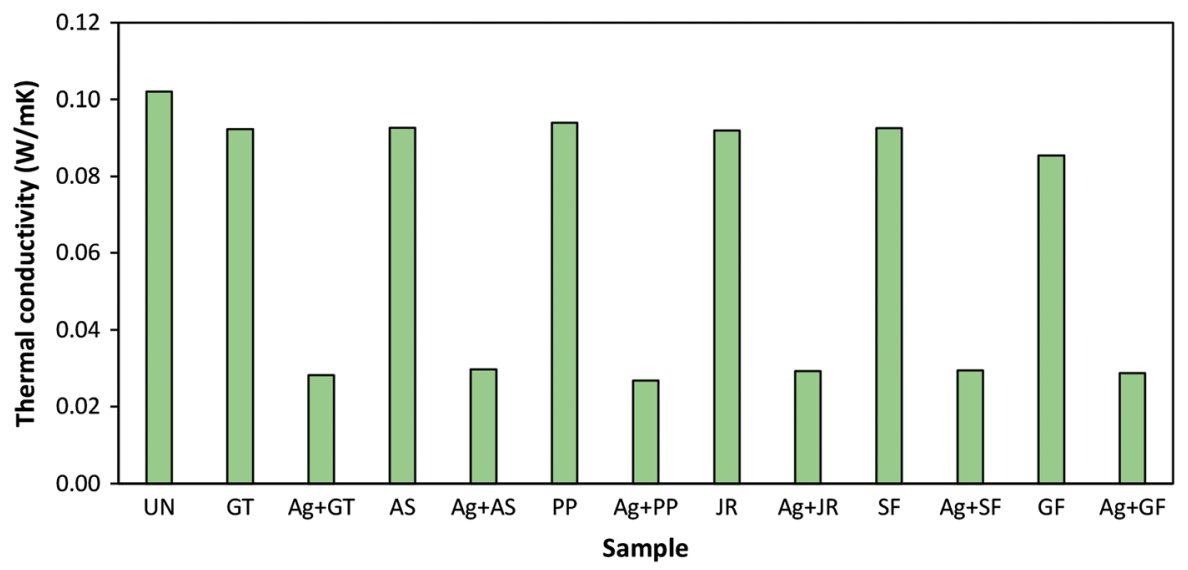

Fig. 9 Thermal conductivity $(\mathrm{W} / \mathrm{mK})$ of untreated and functionalised cotton fabrics: $U N$ untreated, $G T$ green tea extract, $A g+G T \mathrm{Ag}+$ green tea extract, $A S$ avocado seed extract, $A g+A S \mathrm{Ag}+$ avocado seed extract, $P P$ pomegranate peel extract, $A g+P P \mathrm{Ag}+$ pomegranate peel extract, $J R$ Japanese

functionalised with avocado seed, staghorn sumac fruit and Japanese knotweed rhizome extract (samples $\mathrm{AS}, \mathrm{Ag}+\mathrm{AS}, \mathrm{SF}, \mathrm{Ag}+\mathrm{SF}, \mathrm{JR}, \mathrm{Ag}+\mathrm{JR}$ ), while it decreases for the samples functionalised with pomegranate peel extract (samples $\mathrm{PP}$ and $\mathrm{Ag}+\mathrm{PP}$ ). Nevertheless, the differences of higher and lower breaking strength vary only by $3.7 \%$ and $8.1 \%$, respectively, and thus do not change the properties significantly. knotweed rhizome extract, $A g+J P A g+$ Japanese knotweed rhizome extract, $S F$ staghorn sumac fruit extract, $A g+S F$ $\mathrm{Ag}+$ staghorn sumac fruit extract, $G F$ goldenrod flowers extract, $A g+G F \mathrm{Ag}+$ goldenrod flowers extract

\section{Conclusions}

This research shows that water extracts of plants from food waste and invasive alien species can be used as reducing agents for in-situ synthesis of silver nanoparticles on cotton fabric. All the selected plant materials successfully promoted the formation of round silver nanoparticles on cotton fabrics and imparted excellent protective properties to the cellulose fabrics against $E$. coli and $S$. aureus bacteria, and UV radiation. Avocado seed and Japanese knotweed rhizome extracts were found to be the most prominent reducing 


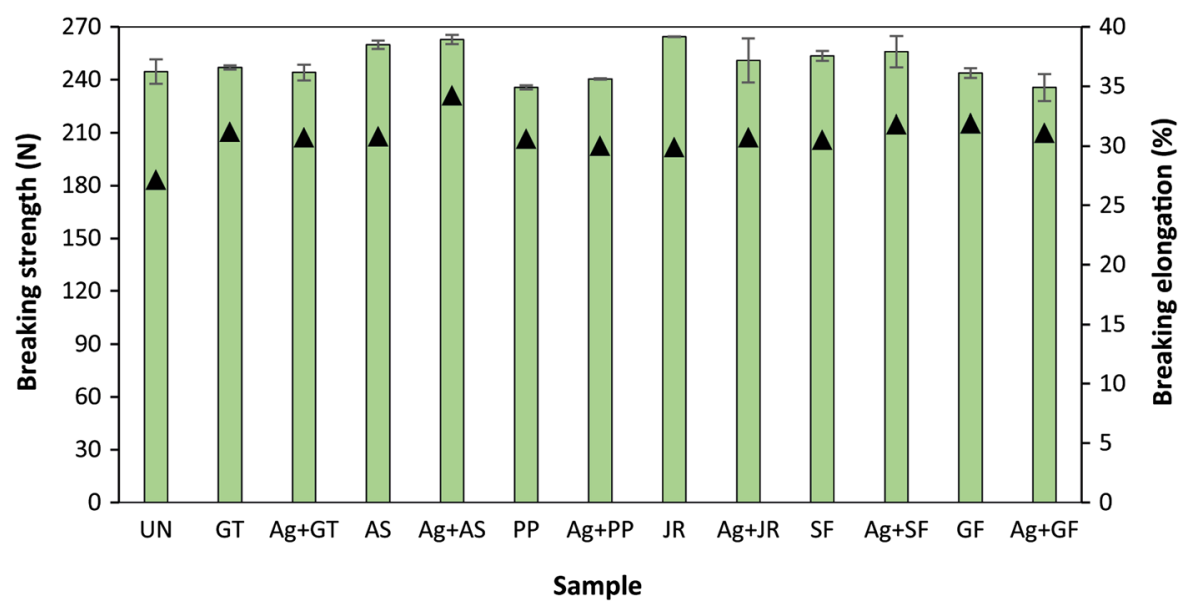

Fig. 10 Breaking strength (N) and breaking elongation (\%) of untreated and functionalised cotton fabrics: $U N$ untreated, $G T$ green tea extract, $A g+G T \mathrm{Ag}+$ green tea extract, $A S$ avocado seed extract, $A g+A S \mathrm{Ag}+$ avocado seed extract, $P P$ pomegranate peel extract, $J R$ Japanese knotweed rhizome

agents, which was attributed to the stability of the formed AgNPs that provided excellent UV protective properties to the cotton fabrics even after repetitive washing. The formation of silver nanoparticles on cotton fabrics decreased the antioxidant properties of the fabrics, slightly the air permeability and quite strongly the thermal conductivity. The results of this research show that the use of plant waste material for the synthesis of silver nanoparticles directly on the fabric allows low-cost and sustainable production of lightweight, thermally insulating, UV-protective and antibacterial cellulosic textiles. The overall results are excellent and give better understanding on using different waste plant material for green synthesis of silver nanoparticles directly on cellulosic substrates.

Acknowledgments The research was financially supported by Slovenian Research Agency (programmes P2-0213 and P10034) and project UIA02-228 APPLAUSE.

Author contributions Conceptualisation, supervision, writing, review M.G., methodology, validation, writing N.Č., formal

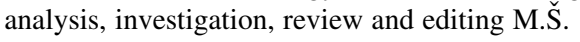

Funding The research was financially supported by Slovenian Research Agency (programmes P2-0213 and P1-0034) and project UIA02-228 APPLAUSE.

\section{Compliance with ethical standards}

Conflict of interest There are no conflicts to declare. extract, $A g+J P A g+$ Japanese knotweed rhizome extract, $S F$ staghorn sumac fruit extract, $A g+S F \mathrm{Ag}+$ staghorn sumac fruit extract, $G F$ goldenrod flowers extract, $A g+G F$ $\mathrm{Ag}+$ goldenrod flowers extract

Open Access This article is licensed under a Creative Commons Attribution 4.0 International License, which permits use, sharing, adaptation, distribution and reproduction in any medium or format, as long as you give appropriate credit to the original author(s) and the source, provide a link to the Creative Commons licence, and indicate if changes were made. The images or other third party material in this article are included in the article's Creative Commons licence, unless indicated otherwise in a credit line to the material. If material is not included in the article's Creative Commons licence and your intended use is not permitted by statutory regulation or exceeds the permitted use, you will need to obtain permission directly from the copyright holder. To view a copy of this licence, visit http://creativecommons.org/licenses/by/4.0/.

\section{References}

Ahmad N, Sharma S, Rai R (2012) Rapid green synthesis of silver and gold nanoparticles using peels of Punica granatum. Adv Mater Lett 3:1-13

Akbal A, Turkdemir MH, Cicek A, Ulug B (2016) Relation between silver nanoparticle formation rate and antioxidant capacity of aqueous plant leaf extracts. J Spectrosc 2016:1-6

Aladpoosh R, Montazer M, Samadi N (2014) In situ green synthesis of silver nanoparticles on cotton fabric using Seidlitzia rosmarinus ashes. Cellulose 21:3755-3766

Ali A, Nguyen NHA, Baheti V, Ashraf M (2018) Electrical conductivity and physiological comfort of silver coated cotton fabrics. J Text Inst 109:620-628

Annavaram V, Posa VR, Uppara VG, Jorepalli S, Somala AR (2015) Facile green synthesis of silver nanoparticles using Limonia acidissima leaf extract and its antibacterial activity. Bionanoscience 5:97-103 
Attia GH, Alyami HS, Orabi MAA, Gaara AH, El Raey AM (2020) Antimicrobial activity of silver and zinc nanoparticles mediated by eggplant green calyx. Int J Pharmacol 16:236-243

Bachir G, Abouni B (2015) Escherichia coli and Staphylococcus aureus most common source of infection. In: Méndez-Vilas A (ed) The battle against microbial pathogens: basic science, technological advances and educational programs. Formatex Research Center, Spain, pp 637-648

Barani H, Mahltig B (2020) Using microwave irradiation to catalyze the in-situ manufacturing of silver nanoparticles on cotton fabric for antibacterial and UV-protective application. Cellulose 27:9105-9121

Boligon AA, Athayde ML (2014) Importance of HPLC in analysis of plants extracts. Austin Chromatogr 1:1-2

Chattopadhyay DP, Patel BH (2009) Improvement in physical and dyeing properties of natural fibres through pre-treatment with silver nanoparticles. Indian J Fibre Text Res 34:368-373

Cheng TH, Yang ZY, Tang RC, Zhai AD (2020) Functionalization of silk by silver nanoparticles synthesized using the aqueous extract from tea stem waste. J Mater Res Technol 9:4538-4549

Cinelli M, Coles SR, Nadagouda MN, Błaszczyński J, Słowiński R, Varma RS, Kirwan K (2015) A green chemistry-based classification model for the synthesis of silver nanoparticles. Green Chem 17:2825-2839

Czajkowski W, Paluszkiewicz J (2008) Synthesis of bifunctional monochlorotriazine reactive dyes increasing UVprotection properties of cotton fabrics. Fibres Text East Eur 16:122-126

Dahoumane SA, Mechouet M, Wijesekera K, Filipe CDM, Sicard C, Bazylinski DA, Jeffryes C (2017) Algae-mediated biosynthesis of inorganic nanomaterials as a promising route in nanobiotechnology - a review. Green Chem 19:552-587. https://doi.org/10.1039/c6gc02346k

Das G, Patra JK, Debnath T, Ansari A, Shin HS (2019) Investigation of antioxidant, antibacterial, antidiabetic, and cytotoxicity potential of silver nanoparticles synthesized using the outer peel extract of Ananas comosus (L.). PLoS ONE 14:1-19

Dash SS, Samanta S, Dey S, Giri B, Dash SK (2020) Rapid green synthesis of biogenic silver nanoparticles using Cinnamomum tamala leaf extract and its potential antimicrobial application against clinically isolated multidrugresistant bacterial strains. Biol Trace Elem Res 198:681-696

Elshaarawy RFM, Seif GA, El-Naggar ME, Mostafa TB, ElSawi EA (2019) In-situ and ex-situ synthesis of poly-(imidazolium vanillyl)-grafted chitosan/silver nanobiocomposites for safe antibacterial finishing of cotton fabrics. Eur Polym J 116:210-221

El-Shishtawy RM, Asiri AM, Abdelwahed NAM, Al-Otaibi MM (2011) In situ production of silver nanoparticle on cotton fabric and its antimicrobial evaluation. Cellulose $18: 75-82$

Filipic J, Glazar D, Jerebic S, Kenda D, Modic A, Roskar B, Vrhovski I, Stular D, Golja B, Smolej S, Tomsic B, Gorjanc M, Simoncic B (2020) Tailoring of antibacterial and UVprotective cotton fabric by an in situ synthesis of silver particles in the presence of a sol-gel matrix and sumac leaf extract. Tekstilec 63:4-13

Firoozi S, Jamzad M, Yari M (2016) Biologically synthesized silver nanoparticles by aqueous extract of Satureja intermedia C.A. Mey and the evaluation of total phenolic and flavonoid contents and antioxidant activity. J Nanostruct Chem 6:357-364

Ganaie SU, Abbasi T, Abbasi SA (2015) Green synthesis of silver nanoparticles using an otherwise worthless weed mimosa (Mimosa pudica): feasibility and process development toward shape/size control. Part Sci Technol 33:638-644

Ganaie SU, Rajalakshmi R, Abbasi T, Abbasi SA (2019) Green synthesis of silver nanoparticles by coral vine and assessment of their properties. Bioinspired Biomimetic Nanobiomater 8:115-129

Gonzalez AL, Noguez C, Beranek J, Barnard AS (2014) Size, shape, stability, and color of plasmonic silver nanoparticles. J Phys Chem C 118:9128-9136. https://doi.org/10. 1021/jp5018168

Gorenšek M, Gorjanc M, Kovač F (2010) Synthesis of colloidal silver and dyeing of cotton with vat dye. Autex 2010:128-128

Gorjanc M, Kovač F, Gorenšek M (2012) The influence of vat dyeing on the adsorption of synthesized colloidal silver onto cotton fabrics. Text Res J 82:62-69

Gorjanc M, Jazbec K, Sala M, Zaplotnik R, Vesel A, Mozetic M (2014) Creating cellulose fibres with excellent UV protective properties using moist $\mathrm{CF} 4$ plasma and $\mathrm{ZnO}$ nanoparticles. Cellulose 21:3007-3021

Govindarajan M, Rajeswary M, Veerakumar K, Muthukumaran U, Hoti SL, Mehlhorn H, Barnard DR, Benelli G (2016) Novel synthesis of silver nanoparticles using Bauhinia variegata: a recent eco-friendly approach for mosquito control. Parasitol Res 115:723-733

Grace-Lynn C, Darah I, Chen Y, Latha LY, Jothy SL, Sasidharan S (2012) In vitro antioxidant activity potential of Lantadene A, a pentacyclic triterpenoid of lantana plants. Molecules 17:11185-11198

He YQ, Wei FF, Ma ZY, Zhang H, Yang Q et al (2017) Green synthesis of silver nanoparticles using seed extract of Alpinia katsumadai, and their antioxidant, cytotoxicity, and antibacterial activities. RSC Adv 7:39842-39851

Huang D, Ou B, Prior RL (2005) The chemistry behind antioxidant capacity assays. J Agric Food Chem 53:1841-1856

Huang J, Li Q, Sun D, Lu Y, Su Y, Yang X, Wang H, Wang Y, Shao W, He N, Hong J, Chen C (2007) Biosynthesis of silver and gold nanoparticles by novel sundried Cinnamomum camphora leaf. Nanotechnology 18:1-11

Husen A, Siddiqi KS (2014) Phytosynthesis of nanoparticles: concept, controversy and application. Nanoscale Res Lett 9:1-24

Ibrahim HMM (2015) Green synthesis and characterization of silver nanoparticles using banana peel extract and their antimicrobial activity against representative microorganisms. J Radiat Res Appl Sci 8:265-275

Ibrahim HM, Zaghloul S, Hashem M, El-Shafei A (2020) A green approach to improve the antibacterial properties of cellulose based fabrics using Moringa oleifera extract in 
presence of silver nanoparticles. Cellulose. https://doi.org/ 10.1007/s10570-020-03518-7

Jadav K, Ninge KN (2017) Antioxidant property of cotton fabric dyed with natural dye extracted from bark peel of Araucaria columnaris. Mater Sci 4:21-26

Jain D, Daima HK, Kachhwaha S, Kothari SL (2009) Synthesis of plant-mediated silver nanoparticles using papaya fruit extract and evaluation of their anti microbial activities. Dig J Nanomater Biostruct 4:557-563

Jha AK, Prasad K (2016) Green synthesis and antimicrobial activity of silver nanoparticles onto cotton fabric: an amenable option for textile industries. Adv Mater Lett 7:42-46

Jiang S, Miao D, Yang G, Chen Z, Li A, Shang S (2015) Fabrication of Ag thin film on polyester fabric by roll to roll magnetron sputtering system. J Mater Sci Mater Electron 26:3364-3369

Karkri M, Lachheb M, Nogellova Z, Boh B, Sumiga B, AlMaadeed MA, Fethi A, Krupa I (2015) Thermal properties of phase-change materials based on high-density polyethylene filled with micro-encapsulated paraffin wax for thermal energy storage. Energy Build 88:144-152

Kashkouli S, Jamzad M, Nouri A (2018) Total phenolic and flavonoids contents, radical scavenging activity and green synthesis of silver nanoparticles by Laurus nobilis L. leaves aqueous extract. J Med Plants By-Prod 7:25-32

Katırcı N, Işık N, Güpür Ç, Guler HO, Gursoy O, Yilmaz Y (2020) Differences in antioxidant activity, total phenolic and flavonoid contents of commercial and homemade tomato pastes. J Saudi Soc Agric Sci 19:249-254

Kausar R, Shaheen MA, Maqbool Q, Naz S, Nazar M, Abbas F, Hussain T, Younas U, Shams MF (2016) Facile biosynthesis of Ag-NPs using Otostegia limbata plant extract: physical characterization and auspicious biological activities. AIP Adv 6, art. no. 095203. https://doi.org/10.1063/1. 4962660

Kert M, Jazbec K, Černe L, Jerman I, Gorjanc M (2014) The influence of nano-ZnO application methods on UV protective properties of cotton. Acta Chim Slov 61:587-594

Khalil MMH, Ismail EH, El-Baghdady KZ, Mohamed D (2014) Green synthesis of silver nanoparticles using olive leaf extract and its antibacterial activity. Arab J Chem 7:1131-1139

Le Ouay B, Stellacci F (2015) Antibacterial activity of silver nanoparticles: a surface science insight. Nano Today 10:339-354

Liu H, Lv M, Deng B, Li J, Yu M, Huang Q, Fan C (2014) Laundering durable antibacterial cotton fabrics grafted with pomegranate-shaped polymer wrapped in silver nanoparticle aggregations. Sci Rep 4:1-9

Liu QX, Huang J, Zhang JM, Hong Y et al (2018) Thermal, waterproof, breathable, and antibacterial cloth with a nanoporous structure. ACS Appl Mater Interfaces 10:2026-2032

Logeswari P, Silambarasan S, Abraham J (2015) Synthesis of silver nanoparticles using plants extract and analysis of their antimicrobial property. J Saudi Chem Soc 19:311-317

Maheswari RU (2012) Green synthesis of silver nanoparticles by using rhizome extract of Dioscorea oppositifolia L. and their anti microbial activity against human pathogens. IOSR J Pharm Biol Sci 1:38-42

Malini S, Kumar SV, Hariharan R, Bharathi AP, Devi PR, Hemananthan E (2020) Antibacterial, photocatalytic and biosorption activity of chitosan nanocapsules embedded with Prosopis juliflora leaf extract synthesized silver nanoparticles. Mater Today Proc 21:828-832

Mamatha G, Rajulu AV, Madhukar K (2020) In situ generation of bimetallic nanoparticles in cotton fabric using aloe vera leaf extract, as a reducing agent. $\mathrm{J}$ Nat Fibers 17:1121-1129. https://doi.org/10.1080/15440478.2018. 1558146

Min-Ho J, Hyun-Tak J, Hyung-Min L, Hae-Jun P, Dong-Ho K, Don-Hee P, Suk B (2017) Phytosynthesis of silver and gold nanoparticles using the hot water extract of mixed woodchip powder and their antibacterial efficacy. J Nanomater 2017:1-19

Mohammadinejad R, Karimi S, Iravani S, Varma RS (2016) Plant-derived nanostructures: types and applications. Green Chem 18:20-52. https://doi.org/10.1039/C5GC01403D

Noman MT, Petru M, Amor N et al (2020) Thermophysiological comfort of zinc oxide nanoparticles coated woven fabrics. Sci Rep 10:1-12

Onitsuka S, Hamada T, Okamura H (2019) Preparation of antimicrobial gold and silver nanoparticles from tea leaf extracts. Colloids Surf B 173:242-248

Park J (2020) Functional fibers, composites and textiles utilizing photothermal and joule heating. Polymers 12:1-25

Parthasarathy S, Azizi JB, Ramanathan S, Ismail S, Sasidharan S, Said MIM, Mansor SM (2009) Evaluation of antioxidant and antibacterial activities of aqueous, methanolic and alkaloid extracts from Mitragyna speciosa (Rubiaceae Family) leaves. Molecules 14:3964-3974

Perera S, Bhushan B, Bandara R, Rajapakse G, Rajapakse S, Bandara C (2013) Morphological, antimicrobial, durability, and physical properties of untreated and treated textiles using silver-nanoparticles. Colloids Surf A 436:975-989

Rao AV, Ashok B, Mahesh MU, Subbareddy GV, Sekhar VC, Ramanamurthy GV, Rajulu AV (2019) Antibacterial cotton fabrics with in situ generated silver and copper bimetallic nanoparticles using red sanders powder extract as reducing agent. Int J Polym Anal Charact 24:346-354

Ravindra S, Mohan YM, Reddy NN, Raju KM (2010) Fabrication of antibacterial cotton fibres loaded with silver nanoparticles via "Green Approach." Colloids Surf A 367:31-40

Reddy MC, Murthy KSR, Srilakshmi A, Sambasiva Rao KRS, Pullaiah T (2015) Phytosynthesis of eco-friendly silver nanoparticles and biological applications-a novel concept in nanobiotechnology. Afr J Biotechnol 14:222-247

Rehan M, Barhoum A, Van Assche G, Dufresne A, Gätjen L, Wilken R (2017) Towards multifunctional cellulosic fabric: UV photo-reduction and in-situ synthesis of silver nanoparticles into cellulose fabrics. Int J Biol Macromol 98:877-886

Rehan M, Elshemy NS, Haggag K, Montaser AS, Ibrahim GE (2020) Phytochemicals and volatile compounds of peanut red skin extract: simultaneous coloration and in situ synthesis of silver nanoparticles for multifunctional viscose fibers. Cellulose 27:9893-9912 
Sahgal G, Ramanathan S, Sasidharan S, Mordi MN, Ismail S, Mansor SM (2009) In vitro antioxidant and xanthine oxidase inhibitory activities of methanolic Swietenia mahagoni seed extracts. Molecules 14:4476-4485

Sayed U, Tiwari R, Dabhi P (2015) UV protection finishes on textile fabrics. Int J Adv Sci Eng 1:56-63

Shahid-ul-Islam BBS, Kumar A (2020) Green chemistry based in-situ synthesis of silver nanoparticles for multifunctional finishing of chitosan polysaccharide modified cellulosic textile substrate. Int J Biol Macromol 152:1135-1145

Shahid-ul-Islam BBS, Gupta A, Roy A (2019) Multifunctional finishing of cellulosic fabric via facile, rapid in-situ green synthesis of AgNPs using pomegranate peel extract biomolecules. Sustain Chem Pharm 12:1-8

Shaid A, Fergusson M, Wang L (2014) Thermophysiological comfort analysis of aerogel nanoparticle incorporated fabric for fire fighter's protective clothing. Chem Mater Eng 2:37-43

Sheikh J, Bramhecha I (2019) Multi-functionalization of linen fabric using a combination of chitosan, silver nanoparticles and Tamarindus Indica L. seed coat extract. Cellulose 26:8895-8905

Singh A, Sheikh J (2020) Cleaner functional dyeing of wool using Kigelia Africana natural dye and Terminalia chebula bio-mordant. Sustain Chem Pharm 17:1-6

Sivaranjana P, Nagarajan ER, Rajini N, Ayrilmis N, Rajulu AV, Siengchin S (2019) Preparation and characterization studies of modified cellulosic textile fabric composite with in situ-generated AgNPs coating. J Ind Text. https://doi. org/10.1177/1528083719855312

Stankovic SB, Novakovic M, Popovic DM, Poparic GB, Bizjak M (2019) Novel engineering approach to optimization of thermal comfort properties of hemp containing textiles. J Text Inst 110:1271-1279

Tang SH, Zheng J (2018) Antibacterial activity of silver nanoparticles: structural effects. Adv Healthc Mater 7:1701503-1701503

Tang B, Lin X, Zou F, Fan Y, Li D, Zhou J, Chen W, Wang X (2017) In situ synthesis of gold nanoparticles on cotton fabric for multifunctional applications. Cellulose 24:4547-4560

Tania IS, Ali M, Azam S (2018) In-situ synthesis and characterization of silver nanoparticle decorated cotton knitted fabric for antibacterial activity and improved dyeing performance. SN Appl Sci 64:1-9
Türkoğlu GC, Sariişik AM, Erkan G, Kayalar H, Kontart O, Öztuna S (2017) Determination of antioxydant capacity of capsule loaded textiles. Indian J Fibre Text Res 42:189-195

Ugur SS, Sariisik M, Aktas AH (2010) The fabrication of nanocomposite thin films with $\mathrm{TiO} 2$ nanoparticles by the layer-by-layer deposition method for multifunctional cotton fabrics. Nanotechnology 21:325603-325603

Velmurugan P, Kim JI, Kim K, Park JH, Lee KJ, Chang WS, Park YJ, Cho M, Oh BT (2017) Extraction of natural colorant from purple sweet potato and dyeing of fabrics with silver nanoparticles for augmented antibacterial activity against skin pathogens. J Photochem Photobiol B 173:571-579

Wang W, Liang YC, Yang ZX, Zhang W, Wang S (2019) Construction of ultraviolet protection, thermal insulation, superhydrophobic and aromatic textile with Al-doped $\mathrm{ZnO}$-embedded lemon microcapsule coatings. Text Res J 89:3860-3870

Yap YH, Azmi AA, Mohd NK, Yong FSJ, Kan SY, Thirmizir MZA, Chia PW (2020) Green synthesis of silver nanoparticle using water extract of onion peel and application in the acetylation reaction. Arab J Sci Eng 45:4797-4807

Yazdanshenas ME, Shateri-Khalilabad M (2012) The effect of alkali pre-treatment on formation and adsorption of silver nanoparticles on cotton surface. Fibers Polym 13:1170-1178

Yu ZC, He HL, Liu JR, Li YQ, Lin XB, Zhang CB, Li MH (2020) Simultaneous dyeing and deposition of silver nanoparticles on cotton fabric through in situ green synthesis with black rice extract. Cellulose 27:1829-1843

Yuranova T, Rincon AG, Bozzi A, Parra S, Pulgarin C, Albers P, Kiwi J (2003) Antibacterial textiles prepared by RF-plasma and vacuum-UV mediated deposition of silver. J Photochem Photobiol A 161:27-34

Zhou QQ, Lv JC, Ren Y, Chen JY, Gao DW, Lu ZQ, Wang CX (2017) A green in situ synthesis of silver nanoparticles on cotton fabrics using aloe vera leaf extraction for durable ultraviolet protection and antibacterial activity. Text Res J 87:2407-2419

Publisher's Note Springer Nature remains neutral with regard to jurisdictional claims in published maps and institutional affiliations. 